\title{
AIDS, drought, and child malnutrition in southern Africa
}

\author{
John B Mason ${ }^{1, *}$, Adam Bailes ${ }^{1} \uparrow$, Karen E Mason², Olivia Yambi ${ }^{3} \mp$, Urban Jonsson ${ }^{3} \S$, \\ Claudia Hudspeth $^{4}$, Peter Hailey ${ }^{5}$, Andrea Kendle ${ }^{6}$, Dominique Brunet ${ }^{7}$ and Pierre Martel ${ }^{8}$ \\ 'Department of International Health and Development, Tulane University School of Public Health and Tropical \\ Medicine, 1440 Canal Street, Suite 2200, New Orleans, LA 701 18, USA: ${ }^{2}$ School of Public Health, Lovisiana State \\ University, New Orleans, LA, USA: ${ }^{3}$ United Nations Children's Fund (UNICEF), Eastern and Southern Africa Regional \\ Office (ESARO), Nairobi, Kenya: ${ }^{4}$ UNICEF, Regional Inter-Agency Coordination Support Office (RIACSO), \\ Johannesburg, South Africa: ${ }^{5}$ UNICEF, Malawi: ${ }^{6} U N I C E F$, Johannesburg, South Africa: ${ }^{7}$ UNICEF, Zambia: ${ }^{8}$ UNICEF, \\ Mozambique and Lesotho
}

Submitted 8 June 2004: Accepted 17 February 2005

\begin{abstract}
Objective: To investigate trends in child malnutrition in six countries in southern Africa, in relation to the HIV epidemic and drought in crop years 2001/2 and 2002/3. Design: Epidemiological analysis of sub-national and national surveys with related data.

Setting: Data from Lesotho, Malawi, Mozambique, Swaziland, Zambia and Zimbabwe, compiled and analysed under UNICEF auspices.

Subjects: Secondary data: children $0-5$ years for weight-for-age; HIV prevalence data from various sources especially antenatal clinic surveillance.

Results: Child nutritional status as measured by prevalence of underweight deteriorated from 2001 onwards in all countries except Lesotho, with very substantial increases in some provinces/districts (e.g. from 5 to 20\% in Maputo (Mozambique, 1997-2002), 17 to 32\% in Copperbelt (Zambia, 1999-2001/2) and 11 to 26\% in Midlands province (Zimbabwe, 1999-2002)). Greater deterioration in underweight occurred in better-off areas. Areas with higher HIV/AIDS prevalences had (so far) lower malnutrition rates (and infant mortality rates), presumably because more modern areas - with greater reliance on trade and wage employment - have more HIV/AIDS. Areas with higher HIV/AIDS showed more deterioration in child nutrition. A significant area-level interaction was found of HIV/AIDS with the drought period, associated with particularly rapid deterioration in nutritional status.

Conclusions: First, the most vulnerable may be households in more modern areas, nearer towns, to whom resources need to be directed. Second, the causes of this vulnerability need to be investigated. Third, HIV/AIDS amplifies the effect of drought on nutrition, so rapid and effective response will be crucial if drought strikes again Fourth, expanded nutritional surveillance is now needed to monitor and respond to deteriorating trends. Finally, with or without drought, new means are needed of bringing help, comfort and assistance to the child population.
\end{abstract}

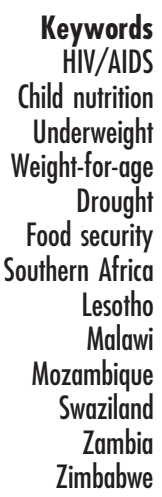

Keywords

(1)

Underweight

Weight-for-age

Drought

Food security Malawi mbique Zambia Zimbabwe
A 'lethal combination of factors' ${ }^{1}$ came together in 2001/2 to cause a severe crisis in food availability throughout much of southern Africa. Drought was a major cause, but the crisis was more extensive than in the worse drought of 1991/2. These factors included worsening poverty, market failures and economic decline, conflict and political upheavals especially in Zimbabwe. In Malawi drought

†Presently Consultant to UNICEF, RIACSO, Johannesburg, South Africa.

$\neq$ Presently UNICEF Representative, Laos.

\$Presently Special Advisor on Human Rights to the Executive Director, UNICEF. was slight, yet hundreds of famine deaths were reported in 2002, ascribed to a complex of events triggered by localised flooding and exacerbated by ill-advised sale of grain reserves, and delayed action by government and donors $^{2}$. Underlying all these events was the worsening epidemic of HIV/AIDS, destroying governance and livelihoods.

Prevalences of AIDS increased rapidly in the late 1980s-1990s in six countries of southern Africa studied as described here (Lesotho, Malawi, Mozambique, Swaziland, Zambia and Zimbabwe). The prevalences estimated in antenatal clinics ${ }^{3}$ in urban and peri-urban areas (Table 1) rose initially within $1-4$ years from about 
Table 1 Take-off of HIV infection in pregnant women from HIV sentinel surveillance sites ${ }^{1}$

\begin{tabular}{lcccc}
\hline Country & Year, early prevalence & Take-off year, prevalence & Peak year(s), prevalence & $\begin{array}{c}\text { Most recent } \\
\text { prevalence }\end{array}$ \\
\hline Lesotho & $1993,6 \%$ & $1994,31 \%$ & $2000,42 \%$ & $2000,42 \%$ \\
Malawi & $1987,8 \%$ & $1989,17 \%$ & $1992-1999,25 \%$ & $2001,20 \%$ \\
Mozambique & $1996,6 \%$ & $1998,11 \%$ & $2000,14 \%$ & $2000,14 \%$ \\
Swaziland & $1992,4 \%$ & $1993,22 \%$ & $1998-2000,30 \%$ & $2000,32 \%$ \\
Zambia & $1987,12 \%$ & $1990,25 \%$ & $1992-2001,27-31 \%$ & $2001,31 \%$ \\
Zimbabwe & $1989,10 \%$ & $1993,26 \%$ & $1994,36 \%$ & $2000,31 \%$ \\
\hline
\end{tabular}

$10 \%$ to $20 \%$ or more, continuing to climb to $30-40 \%$ and then remaining around this high level ${ }^{4}$. The exception is Mozambique, which is only recently showing this rise.

AIDS is fuelling a vicious spiral into destitution in households with sick adults ${ }^{5,6}$. This is illustrated in Fig. 1. Poverty and malnutrition reduce disease defences, hastening progression to AIDS, and probably increasing biological vulnerability to primary infection with HIV. Chronic sickness reduces productivity, exacerbates poverty and malnutrition, and increases vulnerability (both biological and behavioural, e.g. fostering transactional sex as a last resort). Sickness is leading to sale of last assets for medicines, which are unlikely to affect the outcome. This process is likely to be much worsened by drought in these agriculture-dependent countries. Worsening poverty in the household can affect child nutrition (measured by anthropometry), in line with the United Nations Children's Fund (UNICEF) conceptual framework for malnutrition ${ }^{7,8}$, by reducing one or more of the underlying causes: household food security, access to health services and health environment, and caring capacity. The latter may be of particular consequence with sick parents and when a parent dies - not only for direct care such as feeding and hygiene, but for emotional reasons as well. Serious effects on child health and development are to be expected from HIV/AIDS in affected households and communities, the more so with increased stress in times of drought: this is an aspect of what has been termed the "new variant famine"?

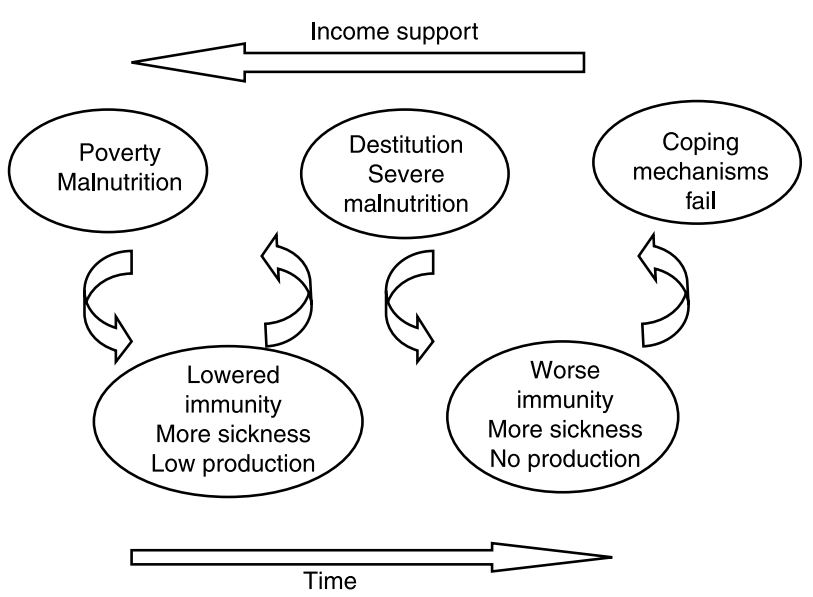

Fig. 1 Spiral of destitution and malnutrition caused by HIV/AIDS
Severe drought hit in the growing season of 2002 (roughly January-April), reducing yields and rapidly inflating food prices, affecting at least half the population in the region. The international community responded with extensive food aid from around June 2002 to March 2003. National governments and regional and inter-agency groups (based on the Southern African Development Community/Food, Agricultural and Natural Resources (SADC/FANR)) monitored the situation through Vulnerability Assessment Committees (VAC), typically with estimates of need based on crop assessments, with some surveys of food security and coping mechanisms. VAC reports were issued twice up to March $2003^{10,11}$.

Maternal-to-child transmission causes a significant number of babies to be HIV-positive; at 20\% transmission ${ }^{12}$, this implies that $5-10 \%$ of children under 5 years of age could be infected in these countries. Children with AIDS exhibit growth failure ${ }^{13,14}$, becoming underweight and malnourished. Adults, both women and men, are falling chronically sick - more than $30 \%$ in parts of Lesotho ${ }^{15}-$ usually men before women; thus the productive household members are hit early, reducing household income, moreover at a time when sick members need additional care. These populations are more vulnerable than ever to economic shocks, including drought.

AIDS and drought thus may increase child malnutrition both directly through children's illness, and indirectly through impoverishment and destitution of households. United Nations (UN) officials described the situation in early 2003 as: '14.4 million people in Southern Africa are at risk of starvation, ${ }^{16}$. The Inter-Agency Standing Committee and Joint United Nations Programme on HIV/AIDS (UNAIDS) added: 'all indications point towards nothing short of a decimation of populations in their most productive years, and the prospect of economic collapse and insecurity in the foreseeable future ${ }^{, 17}$. This continued into 2004, with the focus turning to chronic hunger linked to the AIDS epidemic when James Morris, Director of the World Food Program (WFP), testified before the US Congress on the growing hunger problem around the world and how it is exacerbated by the AIDS crisis ${ }^{, 18}$.

The new threat to child nutrition built on generally static trends in the 1990s in child underweight prevalences ${ }^{19}$ contrasting with other developing regions where prevalences declined; in the countries of southern Africa deterioration was seen in the late 1990s before the recent 
drought $^{20}$. These longer-term trends in sub-Saharan Africa were linked to increased poverty, conflict and failures to increase agricultural productivity, worsened by but not all accounted for by HIV/AIDS ${ }^{19}$.

For the UN agencies, UNICEF took the lead role in monitoring child nutrition. This was based primarily on nutrition surveys: a number done at district level by nongovernment organisations (NGOs) in Malawi and Zambia, and national surveys launched for the purpose in Lesotho, Mozambique and Zimbabwe. Preliminary results put forward in February 2003 indicated that wasting in young children had not generally worsened, indeed it remained quite uncommon ${ }^{21}$. This raised issues such as the extent of actual vulnerability in the face of drought; whether the assistance effort had prevented a disaster; whether there were underlying trends that were changing; who was most affected by malnutrition and most vulnerable; and lessons for the assistance programme for the future.

To examine these questions a broader analysis of the data related to recent trends in child nutrition was launched. Three specific questions were addressed. (1) Did child malnutrition change overall, and how were the changes distributed geographically? (2) Did changes in child malnutrition relate to prior malnutrition? (3) How did changes in child malnutrition relate to drought and HIV, and their potential interaction?

Preliminary results were reported to an inter-agency meeting convened by UNICEF and WFP in Johannesburg in April $2003^{22}$ and in an informal report in May $2003^{21}$; the official UNICEF report was issued in early $2004^{23}$. The present paper deals with the key findings and their policy implications.

\section{Data and methods}

\section{Data sources}

Data on child anthropometry in the six countries were obtained from three sources: Demographic and Health Surveys (DHS) 1992-2001 ${ }^{24}$, Multiple Indicator Cluster Surveys (MICS) 1995-2000 25 , and specially initiated national and area-level surveys (a list of surveys by country is provided in the Appendix). Surveys typically adopted a two-stage cluster sampling method designed to be representative at the provincial level (usually about 10 per country). District-level estimates in 2001-2003 for Malawi, Lesotho and Zambia, used to calculate trends, as a rule used a $30 \times 30$ cluster sampling methodology ${ }^{26}$. These data were collected by NGOs in response to the humanitarian crisis in certain areas and were not meant to provide estimates for countries as a whole.

Prevalence rates for HIV/AIDS in adults were obtained via UNAIDS reports for $2002^{3}$, with additional sub-national estimates for Malawi, Zambia and Zimbabwe from three sources: (1) The National AIDS Control Programme, The POLICY Project ${ }^{27}$; (2) DHS 2001 ${ }^{28}$; and (3) VAC Report ${ }^{29}$, respectively (see also Appendix). Estimates for Zambia and Malawi are based on males and females aged 15-49 years, and for Zimbabwe on pregnant women only. Only national estimates were available for Lesotho, Mozambique and Swaziland. HIV estimates were matched with underweight prevalences at area level. It should be noted that these may not refer to the same population groups in particular in terms of migration; and that rural HIV estimates are thought to overestimate the local population prevalences $^{30}$.

Infant mortality rates (IMRs) were taken primarily from reports of the same DHS and MICS surveys that provided the anthropometry. Estimates were measured for 5-10 years prior to the survey. A number of other indicators, e.g. percentage chronically ill, were from VAC reports ${ }^{15}$.

\section{Outcome indicators}

Malnutrition can affect linear growth, leading to low height-for-age, and/or soft tissue, leading to thinness or wasting assessed usually as weight-for-height. Both these can be detected with one measure, weight-for-age, which will therefore have the best chance of picking up changes in child nutritional status. Sudden increases in underweight are due to wasting, because wasting is the immediate response to inadequate food intake (or sickness); but usually weight-for-age is highly correlated with stunting, and weight-for-age will pick up both stunting and wasting. Moreover, weight-for-age is measured in most surveys (like DHS and MICS), its behaviour as an indicator is well understood, and prevalences in a useful range (averaging about 30\%, at below minus two standard deviations $(<-2 \mathrm{SD})$ weightfor-age) are usual in this region. Wasting has lower prevalences in Africa (usually around 5-10\% at $<-2$ SD weight-for-height ${ }^{31}$, so there is a 'rare event' problem: changes in weight-for-height overall will not be readily detected as a prevalence with this cut-off. Thus the primary indicator used was underweight prevalence $(\%$ $<-2$ SD weight-for-age in 6-59-month-old children by international (National Center for Health Statistics/World Health Organization (WHO)) standards). Wasting and stunting prevalences $(<-2 \mathrm{SD}$ height-for-age) were also calculated, but are not presented here as they add little to the findings based on weight-for-age; in fact, as discussed below, wasting did not increase significantly as measured in the sub-national surveys conducted during the drought.

Previous analyses of the data from NGO-supported surveys had focused on wasting ${ }^{11}$, on the premise that conditions were comparable to other recent complex emergencies, with displacement and conflict as major causes of malnutrition. In practice, wasting prevalences were not found to change substantially and underweight was more responsive to the situation - implying that rates of deterioration may have been slower than with displacement and that declines in linear growth (stunting) contributed. This observation that wasting did not increase 
much caused difficulties in understanding effects on malnutrition (see reference 11, p. 7); but stresses the utility of starting with a non-specific measure like underweight that will pick up any changes that are happening.

Validation/reliability of nutritional trend indicators Reliable assessment of trends in nutritional status depends on the comparability of the surveys over time. For all surveys, four aspects were examined to assess the comparability of nutritional status indicators in children: sampling frame; ages of children; sample sizes; and timing of surveys, particularly with respect to seasonality. Seasonality is important in this region and there is limited experience in dealing with it in estimating trends in child underweight, which can change by more than 5 percentage points between seasons ${ }^{23}$ compared with a long-term trend often around 1 percentage point per year or less. Thus failure to account for seasonality can readily give spurious estimates of longer trends. Surveys should preferably be conducted at the same times of the year to avoid these in-built fluctuations in nutritional status. Here, the timing of surveys was examined and expectations of seasonal changes were taken into account ${ }^{23}$; seasonal timing of surveys is shown in Table 2 .

\section{Age adjustments}

The prevalence of malnutrition is commonly greatest in the most vulnerable age group, 12-36-month-olds. Adjustments in prevalences were necessary whenever different age bands were reported and the raw data were not available, to allow comparisons between sub-national areas (provinces or districts) over time. (While national average results are usually reported for age bands, this is often not so for sub-national areas.) The age adjustment was needed when the age ranges were reported differently for sub-national areas in different surveys, e.g. 5-59 months in one compared with 6-36 months in another. The method was as follows. The survey with the narrowest age bands was used as baseline, and the prevalences to be compared were adjusted to this age band. For example, 6-36 months could be the age band reported for the base prevalence, 0-59 months in the survey to be adjusted; the ratio of the national prevalences at 6-36 months/0-59 months was calculated and applied to the sub-national estimates (if these were not given for the 6-36-month age band), to adjust these to the expected value for 6-36 months. The value of these adjustment factors was usually in the range of 0.8 to 1.2.

\section{Estimation of rates of change}

Changes in underweight prevalences were standardised as percentage points change per year. This is distinct from percentage change - it subtracts the earlier figure in \% from the later figure and divides by number of years between them. For example, if the first estimate is $25 \%$ underweight and the second 30\%, this is 5 percentage points, or 5 ppt, change. (In percentage terms it would be $5 / 25=20 \%$ change.) The sign is defined logically, negative meaning improvement. In the example, an improvement from $30 \%$ to $25 \%$ in 2 years is $-2.5 \mathrm{ppt} /$ year. To give a sense of scale: at national level, + or $-1 \mathrm{ppt} /$ year is a substantial change - underweight does

Table 2 National estimates of underweight prevalence (A) prior to 2001/2 drought and (B) through 2001/2 drought

\begin{tabular}{|c|c|c|c|}
\hline \multirow[b]{2}{*}{ Country } & \multirow[b]{2}{*}{ Survey*, date (season) } & \multicolumn{2}{|c|}{ Prevalence (\%) } \\
\hline & & $6-35$ months & $6-59$ months \\
\hline \multicolumn{4}{|l|}{ A. Before 2001/2 } \\
\hline \multirow[t]{4}{*}{ Malawi } & DHS, Sept-Nov 1992 (midway between harvests, rains) & 33.4 & 30.9 \\
\hline & MICS, Oct 1995 (midway, rains) & 30.7 & 29.9 \\
\hline & DHS, Jul-Nov 2000 (post-harvest) & 32.0 & 27.8 \\
\hline & MNS, Sept-Oct 2001 (midway, rains) & 31.1 & NA \\
\hline \multirow[t]{2}{*}{ Mozambique } & DHS, Mar-Jun 1997 (harvest) & 31.6 & \\
\hline & Quibb, Oct 2000-May 2001 (rains through harvest) & 27.0 & \\
\hline \multirow{3}{*}{ Zambia } & DHS, Jan-May 1992 (lean - harvest) & & 28.0 \\
\hline & DHS, Jul 1996-Jan 1997 (post-harvest - rains) & & 25.9 \\
\hline & MICS, Oct 1999 (midway) & & 25.0 \\
\hline \multirow{2}{*}{ Zimbabwe } & DHS 1988 (midway) & 12.2 & \\
\hline & DHS 1999 (midway) & 15.5 & \\
\hline \multicolumn{4}{|c|}{ B. From before 2001 into 2002} \\
\hline \multirow[t]{2}{*}{ Lesotho } & MICS, Mar-May 2000 (lean - harvest) & & 19.2 \\
\hline & NNEPI, Oct 2002 (post-harvest) & & 17.0 \\
\hline \multirow[t]{2}{*}{ Mozambique, 6 provinces } & DHS, Mar-Jun 1997 (harvest) & 18.4 & \\
\hline & Multi-sectoral survey, Dec 2002 (rains) & 25.5 & \\
\hline \multirow[t]{2}{*}{ Zambia } & MICS, Oct 1999 (midway) & & 25.0 \\
\hline & DHS, Nov 2001-May 2002 (harvest) & & 30.8 \\
\hline \multirow[t]{2}{*}{ Zimbabwe } & DHS, Aug-Nov 1999 (midway - rains) & & 14.3 \\
\hline & National Nutrition Survey, May 2002 (harvest) & & 20.4 \\
\hline
\end{tabular}

NA - not applicable.

* See Appendix for sources. 
not normally change very fast - and at sub-national level more than (say) $2 \mathrm{ppt} /$ year is worth noting ${ }^{32}$. Some of the changes observed here were much higher than usually seen, up to $5 \mathrm{ppt} / \mathrm{year}$.

At the individual level particularly, the pattern of levelling out observed (see Results section) could sometimes be due to a regression artefact or regression to the mean. For example, if a group of children is weighed, and children with the lowest weight-for-age are selected (say, $<-2 \mathrm{SD}$ ) and then re-measured some time later, overall they will usually have improved because some are selected with conditions that will spontaneously get better (e.g. they may have been sick on the day they were originally measured). If only this group is considered, it will tend towards ('regress to') the average ('mean') for the group (the spontaneously recovering individuals will not be balanced by those becoming sick, if only the selected group is considered). In the results here, the apparent levelling out at area level was not thought to be equivalent to such an artefact, for the following reasons. First, looking back at earlier trends by province or district (which was done using the DHS and MICS surveys, as listed in Table 2 ), it was clear that historically this did not happen to any marked extent (see Table 3) - high-prevalence areas tended to remain high, and vice versa. Second, the surveys appeared to be reliable and not changing in reliability (e.g. SDs were not changing through time). Third, there was reason to think that the levelling out was explicable rather than artefactual - in this sense there was indeed regression to the mean, but it was not an artefact of the data.

\section{Ecological analysis of HIV and child nutritional status}

Many variables were available only at aggregate level. An ecological analysis was done to examine the effects of a combination of factors including HIV prevalence on child underweight. The method compares factors measured at a group level, here defined by area, to identify relationships that may give insights into causality. A limitation is that findings may not reflect causality at the individual level, due to associations with other area-specific factors (ecological fallacies), from confounding due to aggregation.

Factors examined at the national and sub-national levels in the six countries were underweight prevalence in under-5s ( $<-2 \mathrm{SD}$ weight-for-age $Z$-score), HIV/AIDS prevalence in adults and IMR. Most information was from DHS or MICS surveys from 1999 or 2000, except for Mozambique $^{33}$. IMRs are mostly measured from the 10 years prior to the survey date (1990-2000). The sample includes both national and sub-national data with most data points from sub-national areas (statistically less accurate but useful in identifying trends). Associations between the variables were examined with correlation and plots. (Under-5 mortality rates (U5MRs) were also examined, but since IMR is highly correlated with U5MR the latter was dropped in further analyses.)

\section{Results}

\section{National trends in underweight before 2001/2}

Available national estimates of child underweight prevalences over the 10 years before the 2001/2 drought are given in Table 2A. The timing of the surveys by season is indicated, some improvement being expected post-harvest. Drought previously affected the region in 1991/2, so the prevalences of underweight in the two 1992 surveys (Malawi and Zambia) may have been elevated at that time. The national prevalences showed little change prior to the drought, except in Zimbabwe where there was some increase in prevalence; but the problems in Zimbabwe encompass land reform and redistribution, political unrest and economic disruption, which undoubtedly increase the risk of malnutrition. It should be noted that food security in Malawi was already a problem in 2000, in part for economic reasons, although rainfall was reduced in 2001/2 and 2002/3, less than elsewhere in the region. In this region the harvest is in April-May; the two cropping periods (i.e. through the harvest) of 2001/2 and $2002 / 3$ were affected by drought in most countries.

\section{National trends in underweight from before 2001 into $2001 / 2$}

Changing trends in malnutrition were assessed by comparing the trends before 2001/2 with those calculated from prevalences before the start of the drought period (i.e. before 2001). National trends could be estimated for Lesotho, Zambia, Zimbabwe, and for six provinces affected in Mozambique, as shown in Table 2B. Lesotho appeared relatively unaffected; indeed, the slight improvement is in line with what might be expected over a harvest period. Mozambique, Zambia and Zimbabwe showed deterioration in child nutritional status: on average, malnutrition (as underweight) increased by $5-7 \mathrm{ppt}$, equivalent to $+1.3,+1.9$ and $+2.2 \mathrm{ppt} /$ year, respectively. These trends are more pronounced in certain sub-national areas, as discussed in the next section.

\section{Sub-national trends in underweight over the drought period}

A number of district-level surveys were conducted during the drought period in Malawi and Zambia, coordinated by UNICEF. These results were compared as feasible with previous estimates extracted from the DHS and MICS datasets.

Separate survey estimates were obtained from 21 districts in Malawi, in August-December 2002 ('NGO surveys'); comparative prevalences for these districts were extracted from the DHS 2000 dataset and from the MICS 1995 dataset. Rates of change in underweight prevalences in 13 districts could be estimated for both periods; these averaged 
Table 3 Trends in child underweight at sub-national level*: (a) trends in periods before and into 2001/2 drought period, and (b) extent to which areas with initially lower underweight prevalences deteriorate more in the later period, and vice versa (referred to as 'crossover')

\begin{tabular}{|c|c|c|c|}
\hline Country & Before 2001 & From before 2001 to during $2001 / 2$ & Comment \\
\hline Malawi districts & $\begin{array}{l}\text { (a) District prevalences } \\
\text { from MICS ' } 95 \text { and DHS '00 } \\
\text { improved by }-0.80 \mathrm{ppt} / \mathrm{year} \\
\text { (b) Limited crossover effect: } \\
\text { slope of underweight } \\
\text { change with starting } \\
\text { prevalence }=-0.1\end{array}$ & $\begin{array}{l}\text { (a) District prevalences } \\
\text { (same } 13 \text { districts) from DHS '00 } \\
\text { to NGO deteriorated by } \\
+0.2 \mathrm{ppt} / \mathrm{year} \\
\text { (b) Stronger crossover effect: } \\
\text { slope of underweight change } \\
\text { with starting prevalence }=-0.2\end{array}$ & $\begin{array}{l}\text { (a) District prevalences improved } \\
\text { earlier, then deteriorated in later } \\
\text { period, but not significant } \\
\text { (b) Over later period districts with } \\
\text { lowest prevalence deteriorate most } \\
\text { and vice versa, more than earlier }\end{array}$ \\
\hline $\begin{array}{l}\text { Mozambique, } \\
6 \text { provinces }\end{array}$ & $\begin{array}{l}\text { (a) No comparable } \\
\text { sub-national data } \\
\text { (age differences), but } \\
\text { unadjusted provincial } \\
\text { prevalences ('95-'97) } \\
\text { show general improvement } \\
\text { in all } 6 \text { provinces } \\
\text { (b) No relation of } \\
\text { improvement to starting } \\
\text { prevalences }\end{array}$ & $\begin{array}{l}\text { (a) Comparing DHS ' } 97 \text { with } \\
\text { Multi-sectoral survey '02 showed } \\
\text { deterioration in all } 6 \text { provinces }\end{array}$ & $\begin{array}{l}\text { (b) Marked tendency for better } \\
\text { provinces to deteriorate and } \\
\text { vice versa through 2002, } \\
\text { not seen earlier }\end{array}$ \\
\hline Zambia districts & No data at district level & $\begin{array}{l}\text { Three districts surveyed (NGO) } \\
\text { in Jun '02, repeated plus one more } \\
\text { in Jan '03. Compared with } \\
\text { district estimates extracted from } \\
\text { MICS '99, two low prevalence } \\
\text { districts increased (18\% to } 25-28 \% \text { ); } \\
\text { two high prevalence districts } \\
\text { improved (38-40\% to } 27-35 \% \text { ) }\end{array}$ & $\begin{array}{l}\text { Consistent with better districts } \\
\text { deteriorating and vice versa } \\
\text { during drought, but few } \\
\text { data points }\end{array}$ \\
\hline Zambia provinces & $\begin{array}{l}\text { (b) Comparing DHS '92 with } \\
\text { DHS '96, no tendency for } \\
\text { crossover }\end{array}$ & $\begin{array}{l}\text { (a) National deteriorating trend } \\
\text { '99-'01/2 seen in most provinces } \\
\text { (not Luapula, Northern, NW, W; } \\
\text { these already highest) } \\
\text { (b) Marked tendency for better } \\
\text { provinces to deteriorate more, } \\
\text { comparing MICS '99 with } \\
\text { DHS '01/2. Results similar } \\
\text { comparing DHS '96 with } \\
\text { DHS '01/2 }\end{array}$ & $\begin{array}{l}\text { (b) Significant crossover seen } \\
\text { comparing provinces over } \\
\text { drought. Little sign of this } \\
\text { pre-drought }\end{array}$ \\
\hline Zimbabwe provinces & $\begin{array}{l}\text { (a) Provincial data from } \\
\text { DHS '94 and DHS '99 } \\
\text { not fully comparable } \\
\text { (age differences) } \\
\text { (b) However some sign } \\
\text { of tendency for crossover }\end{array}$ & $\begin{array}{l}\text { Provincial data from DHS ' } 99 \\
\text { and national nutrition survey } \\
\text { '02 not fully comparable because } \\
\text { of sampling differences; } \\
\text { all provinces deteriorated, } \\
\text { with increased tendency } \\
\text { for better areas to worsen more }\end{array}$ & $\begin{array}{l}\text { Marked deterioration in all } \\
\text { provinces; tendency for better } \\
\text { to worsen more may have started } \\
\text { before drought, but more } \\
\text { marked during drought }\end{array}$ \\
\hline
\end{tabular}

\footnotetext{
${ }^{*}$ See Appendix for sources.
}

Malawi. (a) Districts selected with trend data in both periods, $n=13$; difference in trends, -0.80 cf. $0.20, n=26, P=0.14$. (b) As shown in Fig. 2 , slope of rate of change in underweight prevalence on starting prevalence (MICS or DHS) for first period $=-0.11, P=0.002, n=23$; for second period $=-0.22$, $P=0.004, n=17$. Difference in slopes (interaction) has $P=0.13, n=40$, see Fig. 2. One district (Ntchisi) with $-6.3 \mathrm{ppt} / \mathrm{yr}$ in later period excluded as outlier.

Mozambique. (b) For 1997-2002, slope of rate of change in underweight prevalence on starting prevalence $=-0.08, P=0.01, n=6$.

Zambia. (b) For provinces, 1992-1996, slope of rate of change of underweight prevalence on starting prevalence $=-0.04, P=0.52, n=9$; for $1999-$ 2001, slope $=-0.15, P=0.01, n=9$.

Zimbabwe. (b) For 1994-1999, slope of rate of change in underweight prevalence on starting prevalence $=-0.09, P=0.14, n=6$; for $1999-2002$, slope $=-0.19, P=0.12, n=10$. 


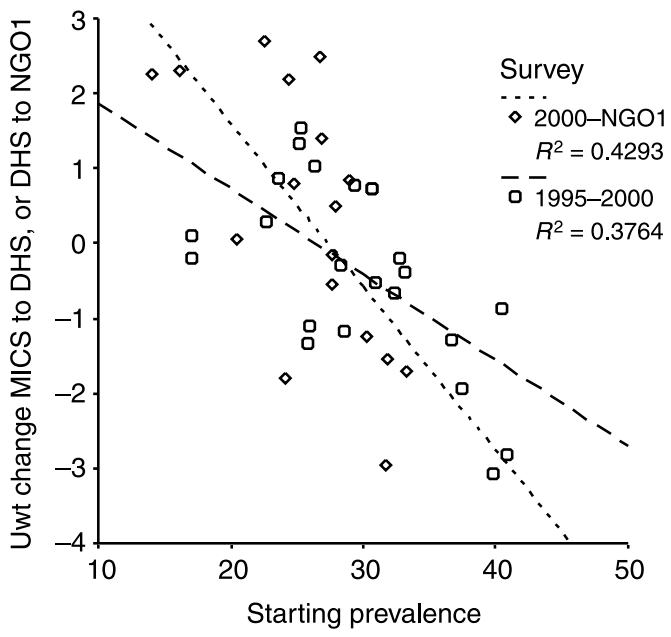

Regression results: Change in underweight (ppt/year) $=3.013-0.114$ (initial prevalence (MICS or DHS)) +2.957 (dummy for survey period $(1=$ through $2000 / 1))-0.104$ (interaction: initial prevalence $\times$ survey period)

$n=40, R^{2}=0.44$; coefficients: initial prevalence, $P=0.004$, dummy for survey period, $P=0.119$, interaction, $P=0.129$

Fig. 2 Malawi: rates of change by district in child underweight prevalences (percentage points (ppt)/year) in relation to starting prevalences, before 2000 and during 2000-2002. Uwt - underweight; MICS - Multiple Indicator Cluster Surveys; DHS - Demographic and Health Surveys; NGO, non-government organisation

the 1995-2000 results having the shallower line in Fig. 2. Slopes in both periods are significant, with the later slope steeper (more negative); comparing the slopes the differences are not significant (the interaction has $P=0.13, n=40$ ), perhaps related to the limited sample size. This tendency to cross over is a potentially important occurrence, more pronounced in the later periods over the drought. As discussed next, this was observed in the other countries' data.

Before the drought there was no significant tendency for better areas to deteriorate and vice versa (for crossover) in Mozambique and Zambia; while in Zimbabwe there was some indication of this, although less than in the drought period. Mozambique and Zambia both showed a significant association (although numbers of provinces are low) for crossover during the drought period (Table 3 ). As examples, in Mozambique prevalences of underweight children (6-36 months) between 1997 and 2002 went from $5.1 \%$ in Maputo to $20.1 \%$, and from $15.8 \%$ to $22.7 \%$ in Sofala, while remaining static at about $30 \%$ in Tete and Manica.

In Zambia, provincial results showed that the prevalence (6-59 months) in Copperbelt, hitherto having the lowest prevalence, went from $17.3 \%$ in 1999 to $31.8 \%$ in 2001/2, and in Eastern Province from $23.0 \%$ to $35.2 \%$. In contrast, in Luapula and Northern provinces the prevalence remained steady at 35-37\% (Table 3).

Nine district survey results were available for Zambia from NGO surveys carried out from June 2002 to February 2003, in six districts of Southern Province, with repeated estimates in four of these. Prevalence estimates for comparison in four of these could be broken out from the MICS 1999 dataset, similarly to the Malawi analysis. Two of these districts (Kaloma and Monze) started with below-average prevalences in 1999 (both 18\%, compared with 23\% for Southern Province overall), and showed increased prevalences. Kaloma increased to $24 \%$ in JuneJuly 2002, with 25\% in January-February 2003; Monze increased to $23 \%$ and $28 \%$ at these times. Two others (Siavonga and Salima) started high in 1999 (40\% and 38\%), and fell to 35\% and 27\% by January-February 2003.

In Zimbabwe, the overall increase from late 1999 to early 2002 from $14.3 \%$ to $20.4 \%$ (Table 2) reflected increases in all provinces, considerably more pronounced in those with lower prevalences in 1999. Thus Midlands deteriorated from $10.9 \%$ in 1999 to $26.3 \%$ in 2002 (the worst increase reported in any of the countries), and Harare from $6.4 \%$ to $14.4 \%$ (see Table 3 ).

Mapping these changes indicated that the greater deterioration was seen in provinces or districts nearer to large towns: near Lilongwe and Blantyre, near Maputo, around Harare and Bulawayo (as well as Midlands in Zimbabwe); in 1999-2001 (i.e. pre-drought) near Lusaka. In contrast, the rural areas showed improvement or stability. The peri-urban areas probably received less food assistance, and may have been more vulnerable to rising food prices. However, HIV/AIDS was also a likely contributor.

\section{Relationship of HIV/AIDS to child underweight prevalences}

HIV/AIDS prevalences are not precisely known, but estimates exist at different aggregation levels for many of the areas for which child nutrition data were reported over the drought period. Plotting child underweight prevalences against HIV/AIDS estimates produces the result, initially counter-intuitive as shown in Fig. 3, that high HIV/ AIDS is associated with lower underweight. These data include results where HIV prevalences and child underweight were matched by sub-national area. As shown in the notes below Fig. 3, the negative association is significant overall, but not for Malawi.

Similar results were obtained plotting IMR by area against HIV - with high HIV associated with low IMR showing that this unexpected result was not a peculiarity of child underweight (and underweight was positively correlated with IMR in the expected way). Child nutrition is usually better in areas near towns, and HIV/AIDS worse, which could explain the direction of the associations.

This also implies that child nutrition has not yet deteriorated, due to the direct and indirect effects of HIV/AIDS, in these areas. However, we would expect to see more deterioration in the low-underweight/high-HIV areas. The association of more deterioration in the low (initial) underweight prevalence 


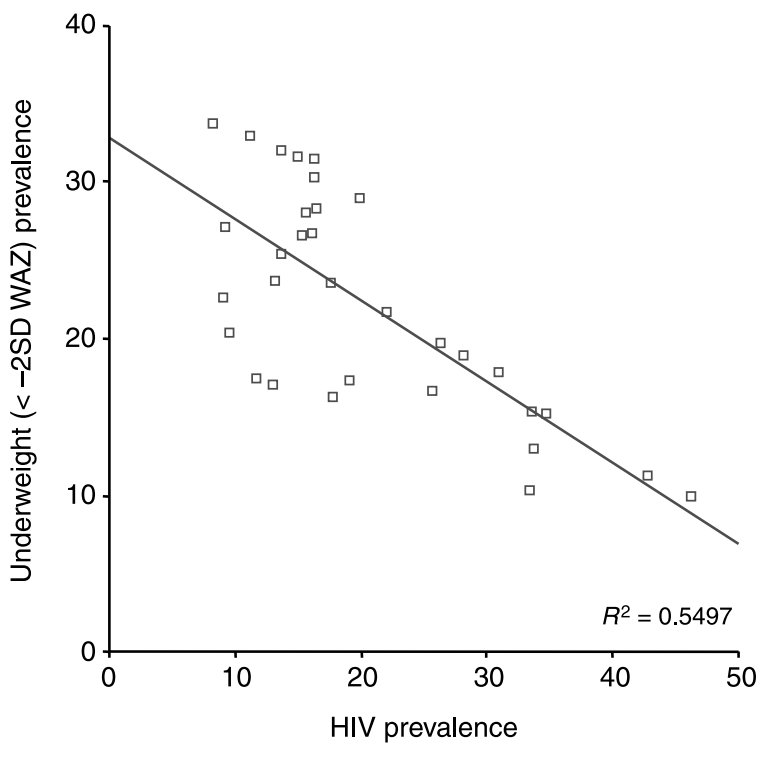

Regression results:

Overall: $\quad B=-0.520, t=-6.051, P=0.000, n=32$

Malawi: $\quad B=0.123, t=0.330, P=0.75, n=10$

Zambia: $\quad B=-0.573, t=-2.172, P=0.062, n=10$

Zimbabwe: $\quad B=-0.254, t=-4.014, P=0.005, n=9$

Fig. 3 Relationship of child underweight prevalence to HIV prevalence, by area in Lesotho, Malawi, Swaziland, Zambia and Zimbabwe. $<-2$ SD WAZ - below minus two standard deviations of weight-for-age Z-score

areas has already been established - in the previous section - and the association of changing underweight with HIV can be examined in a similar way, as described below.

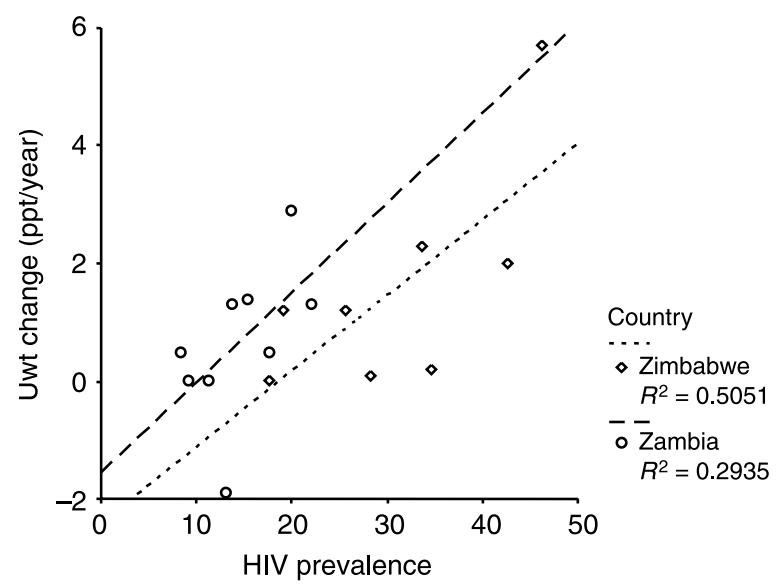

Regression results: Change in underweight prevalence $=-2.548+0.134$ (HIV prevalence) +1.282 (dummy for Zambia)

Coefficients: HIV prevalence, $t=3.228, P=0.006$; dummy for

Zambia (=1), $t=1.401, P=0.183 . R^{2}=0.476, n=17$

Fig. 4 Relationship of rates of change in child underweight prevalence (percentage points (ppt)/year) with HIV prevalence in Zambia (1996 to 2001/2) and Zimbabwe (1999 to 2002). Uwt underweight

\section{Relationship of HIV/AIDS to changes in child underweight prevalences at district/provincial levels}

The relationship between changes in underweight prevalences across the drought period with HIV prevalences (estimates in 2001/2) is shown in Fig. 4, for Zambia (1996 to 2001/2) and Zimbabwe (1999 to 2002), with provinces as the unit of analysis. No relationship was seen in Malawi (districts). The Zambia and Zimbabwe results indicate that child underweight increased in higher HIV areas more than in lower prevalence areas. Only a limited number of data points are available, but the regression suggests that the relationship is significant (see notes below Fig. 4) and that Zambia has a significantly greater deterioration in underweight at a given level of HIV (as the dummy term for Zambia is significant, showing that the two lines in the figure are significantly separated).

The relationship between HIV and rates of change in underweight was not found for the previous inter-survey periods. In other words, the increased change in child malnutrition in higher HIV-affected areas seems so far to have occurred only during the drought period. To establish this point, the interaction between drought period and HIV prevalence was found to be highly significant in regression (ordinary least-squares), as follows:

Change in underweight (ppt/year)

$=-0.162-0.782$ (dummy for drought $(1=$ drought $))$

$-0.01209 \mathrm{HIV}$ prevalence)

+0.104 (interaction: drought $\times$ HIV prevalence)

$n=34, R^{2}=0.49$, coefficients: interaction, $P=0.007$, others not significant (0.4 to 0.6).

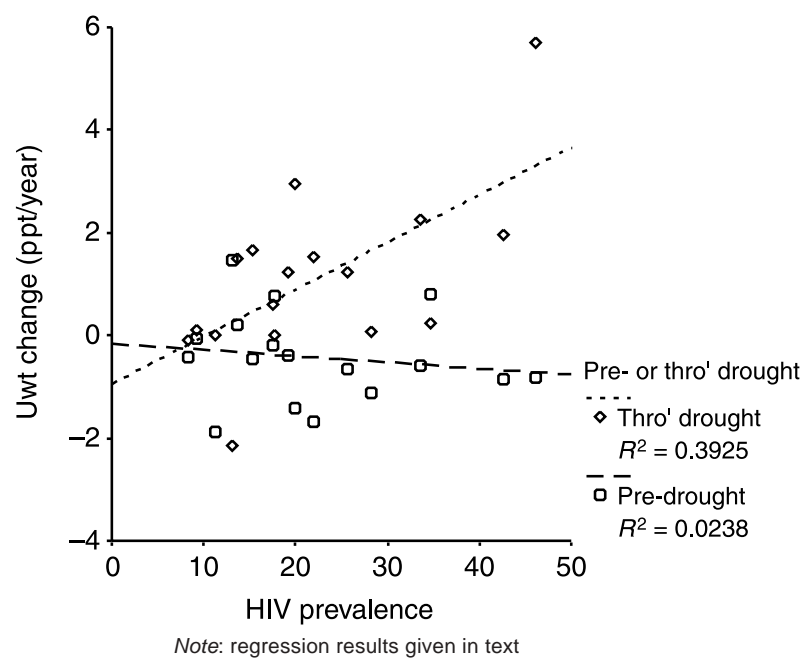

Fig. 5 Interaction between drought and HIV on rates of change in child underweight prevalence (percentage points (ppt)/year), Zambia and Zimbabwe. Uwt - underweight 
This means that the major deterioration is with high HIV in periods of drought; drought significantly worsens the effect of HIV, and HIV significantly worsens the effect of drought. This interaction can be represented as plotted in Fig. 5.

\section{Discussion}

Prevalences of child underweight during the 1990s generally changed little at national average level (Table 2), until the drought in 2001/2. In Malawi and Zambia, the two countries with national data comparable across the 1990s, taking account of poor harvests in 1991/2 and possible seasonal effects, the trends were perhaps of improving child underweight prevalences, about $-0.3 \mathrm{ppt} /$ year. This is in line with other estimates for sub-Saharan Africa $^{31}$, and gives a perspective for the increase of more than $5 \mathrm{ppt}$ seen at national level in Zambia, Zimbabwe, and for six provinces in Mozambique. Over the period between surveys (before 2001 into 2002, Table 2B) this increase amounted to 1.5 to $2 \mathrm{ppt} /$ year - a rapid deterioration in historical terms.

Analysis at sub-national level reveals some worsening trends of alarming magnitude. These were particularly seen in the hitherto lower prevalence areas, mostly near the towns or in more industrialised areas. The areas close to Lilongwe (Malawi) were already badly affected with prevalences of $36 \%$ underweight. In Mozambique, Maputo province increased from 5\% to 20\% (1997 to 2002). In Zambia, Copperbelt increased from 17\% (1999) to $32 \%$ (2001), Eastern Province from 23\% to 35\% over the same period. In Zimbabwe from 1999 to 2002, estimated prevalences in Harare increased from $6 \%$ to $14 \%$, and in Midlands province from $11 \%$ to $26 \%$. These are very large increases. But they were not in the expected places and they led more to a levelling out than to very high prevalences - as might be seen in a 'normal' drought situation. A second key finding is that nutritionally better areas deteriorated more rapidly than those worse off, as illustrated in Fig. 2 and described in Table 3.

While underweight prevalences increased, wasting remained at relatively low levels (well below 10\%). The effects on children of drought and HIV/AIDS therefore appeared to be sustained and of relatively slow onset - at least by the time the surveys were carried out. In preliminary results on the age at which children are most affected it was found that wasting remained relatively low at all ages, and linear height growth was affected increasingly after around 18 months ${ }^{20}$.

The relationship of underweight with HIV could be investigated, even though the HIV prevalence data were collected by different methods (from antenatal clinics). These could be matched approximately by administrative area (province or district). The negative relationship between HIV prevalence and underweight prevalence (Fig. 3), at first sight counter-intuitive, constitutes a third finding. A parallel negative relationship existed for HIV prevalences with IMR (by area), so this is not special to nutrition measurements. The explanation is likely to be that the better-off areas, economically and for service access, have lower child underweight. But these areas are more vulnerable to HIV/AIDS, in fact because of their better conditions, trading and communications. So there is a likely common cause of high HIV and better child nutrition: better socio-economic status (SES) is associated with higher HIV prevalences; and better SES with lower underweight and IMR (these associations are observed in other analyses, not reported here). This does not imply that higher HIV is causally associated with better child nutrition; indeed, controlling for SES the association with child underweight becomes insignificant ${ }^{20}$. If the deterioration in these areas continues, then this relationship will change. These relationships require further investigation. Collecting a range of data on the same households through integrated surveys would be much more preferable, in the future, to linking at the area level as was necessary for the results presented here.

The HIV estimates in rural areas are subject to possible bias in both directions. As WHO has noted ${ }^{30}$, antenatal clinics in rural areas may be in the rural hospitals or large health centres in the larger villages or small towns, so that the more remote areas (with probable lower HIV prevalence) are under-represented. Antenatal clinic data would thus provide an overestimate of the overall area prevalences. On the other hand, antenatal clinic attendance may be reduced for mothers sick with HIV disease unable to easily reach the clinic (although the bias in clinic attendance in general is towards sick people), in which case clinic data would underestimate the actual population prevalence. These opposing tendencies may to some extent balance. The estimates of antenatal clinic/population prevalences (from surveys) given by WHO (reference 30 , p. 9) is about $\pm 15 \%$ (that is, by a factor of $0.85-$ 1.15); and adjusting the lower HIV prevalences in Fig. 3 by this amount would not substantially change the result.

Fourth, the rate of change of underweight was associated in the expected direction (positively associated) with HIV prevalence (Fig. 4). In fact, the slopes were quite steep: an average HIV prevalence of $30 \%$ (see Table 1) is associated with a $2 \mathrm{ppt} /$ year increase in underweight - going (say) from $20 \%$ to $40 \%$ in 10 years. This means that the size of the effect of HIV on nutrition is considerable. Child malnutrition is increasing substantially in high HIV areas. Most of this increase is thought likely to be indirect, rather than representing the effect of paediatric AIDS itself, because this prevalence in the $0-5$ year age group is still quite low, due both to infection rate and the high mortality, and would not account for the rapid increases seen. This is the subject of continuing analysis, including on the age distributions in weight-for-age.

Migration of families with HIV-positive members from rural to urban areas, if these had malnourished children, 
would raise both underweight and HIV prevalences in urban areas - unless the adult HIV prevalences were not picked up. This might be a contributing factor to the increase in underweight prevalence in areas near towns, together with possibly worsening economic conditions in these. The effects of food aid in preferentially holding down the underweight increases in rural areas could not be assessed, but are likely to be minor in the time considered - the coverage was relatively low until 2003, and not clearly oriented away from urban areas ${ }^{20}$.

Fifth: how much was the deteriorating trend in child nutrition, in badly HIV-affected areas, exacerbated by drought? The significant interaction between drought and HIV is important (Fig. 5), showing that each modified the other's effects multiplicatively - the effects more than added together - warning that the combined effects of future drought (or presumably equivalent economic deterioration) could be especially severe. This may well represent an acceleration of the spiral process illustrated in Fig. 1, whereby poverty and malnutrition lower resistance and reduce production, increasing vulnerability further in a vicious cycle until coping mechanisms collapse. It seems crucial to assess whether this accelerated deterioration slows down again in nondrought years, by continuing the survey work and analysis that produced these results.

These results show that child malnutrition is at risk, that surveillance using underweight as a robust indicator is feasible but should be systematised, and stress the urgent need to continue assessment of potentially alarming trends. Newer information needs to be linked to intervention. But while determining the nature of these interventions may require research into causality, the current results themselves direct attention to some needed policy shifts.

First, the most vulnerable may no longer be in the rural areas - traditionally most vulnerable to food insecurity and malnutrition - but they may be the semi-urban households. Resources must be directed towards the groups who appear to be particularly vulnerable. Second, the causes of this vulnerability need to be investigated, so that appropriate interventions can be found. It may be as much problems of failure to care for children - neglect due to family breakdown and stress, as directly to food insecurity itself. Orphans are certainly particularly vulnerable (other results, not given here, showed double the prevalence in Lesotho among children with no parents alive, compared to having either mother or father (or both) alive ${ }^{21}$ ). Third, the fact that the effects are interactive - so very rapid deterioration can occur from a combination of factors - calls for particular care to react quickly and appropriately if drought strikes again, as surely it will before the AIDS epidemic is under control. Finally, even in normal years, HIV will fuel deterioration in child nutrition and well-being. New means of bringing help, comfort and assistance to the child population - most of whom are affected - need support, through schools, community groups and all available means.

\section{Acknowledgements}

The work described here was supported by UNICEF. We thank Professor David Sanders, School of Public Health, University of the Western Cape, Cape Town, for constructive comments; and Professor Paul Hutchinson, Tulane, for advice on regression artefacts. We thank colleagues in UNICEF, WFP, the Food and Agriculture Organization of the UN and many NGOs for providing much contextual information informally.

\section{References}

1 Lambrechts K, Barry G. Why is Southern Africa Hungry? The Roots of Southern Africa's Food Crisis. London: Christian Aid, June 2003, 26 pp. Also available at http://www.christian-aid. org.uk/indepth/0307safrica/safoodcrisis.pdf

2 Devereux S. State of Disaster. Causes, Consequences and Policy Lessons from Malawi. An ActionAid Report. Johannesburg: ActionAid, June 2002, 33 pp. Also available at http://www.actionaidusa.org/pdf/THE\%20MALAWI\%20STATE\%20OF\%20DISASTER\%20Final.pdf

3 Joint United Nations Programme on HIV/AIDS/World Health Organization. Epidemiological Fact Sheets on HIV/AIDS and Sexually Transmitted Infections: 2002 Update [online], 2002. Available at http://www.who.int/GlobalAtlas/PDFFactory/ HIV/index.asp. Accessed March 2003.

4 Asamoah-Odei E, Garcia Calleja JM, Boerma JT. HIV prevalence and trends in sub-Saharan Africa: no decline and large subregional differences. Lancet 2004; 364(9428): 35-40.

5 Piwoz EG, Preble EA. HIV/AIDS and Nutrition: A Review of the Literature and Recommendations for Nutritional Care and Support in Sub-Saharan Africa. SARA Project. Washington, DC: US Agency for International Development, November 2000.

6 Haddad L, Gillespie SR. Effective food and nutrition policy responses to HIV/AIDS: what we know and what we need to know. Journal of International Development 2001; 13: 487-511.

7 United Nations Children's Fund (UNICEF). Strategy for Improved Nutrition of Children and Women in Developing Countries. Policy Review Paper E/ICEF/1990/1.6, JC 27/UNICEF-WHO/89.4. New York: UNICEF, 1990.

8 Mason JB, Hunt J, Parker D, Jonsson U. Improving child nutrition in Asia. Supplement to Food and Nutrition Bulletin 2001; 22(3). Tokyo: United Nations University Press, 2001; 5-80.

9 de Waal A, Whiteside A. New variant famine: AIDS and food, crisis in southern Africa. Lancet 2003; 362(9391): 1234-7.

10 Southern African Development Community (SADC)/Food, Agricultural and Natural Resources (FANR) Vulnerability Assessment Committee. Regional Emergency Food Security Assessment Report. Harare: SAFC/FANR, January 2003.

11 Southern African Development Community (SADC)/Food, Agricultural and Natural Resources (FANR) Vulnerability Assessment Committee. Regional Emergency Food Security Assessment Report. Harare: SAFC/FANR, September 2002.

12 World Health Organization (WHO). New Data on the Prevention of Mother-to-Child Transmission of HIV and their Policy Implications: Conclusions and Recommendations, Technical Consultation on Behalf of the UNFPA/UNICEF/ 
WHO/UNAIDS Inter-Agency Task Team on Mother-to-Child Transmission of HIV. Geneva: WHO, 11-13 October 2000.

13 Henderson RA, Miotti PG, Saavedra JM, Dallabetta G, Chiphangwi J, Liomba $G$, et al. Longitudinal growth during the first 2 years of life in children born to HIV-infected mothers in Malawi, Africa. Pediatric AIDS and HIV Infection 1996; 7(2): 91-7.

14 Bakaki P, Kayita J, Moura Machado JE, Coulter JB, Tindyebwa D, Ndugwa CM, et al. Epidemiologic and clinical features of HIV-infected and HIV-uninfected Ugandan children younger than 18 months. Journal of Acquired Immune Deficiency Syndromes 2001; 28(1): 35-42.

15 Southern African Development Community (SADC)/Food, Agricultural and Natural Resources (FANR) Vulnerability Assessment Committee. Lesotho Emergency Food Security Assessment Report. Harare: SADC/FANR, January 2003.

16 Morris JT. Report of the First Mission to Lesotho, Malawi, Mozambique, Swaziland, Zimbabwe, and Zambia, 3-15 September 2002. Rome: United Nations, 24 September 2002.

17 Inter-Agency Standing Committee and Joint United Nations Programme on HIV/AIDS. Southern Africa's Humanitarian Crisis: Heads of Humanitarian Agencies Call for Action [online], 20 January 2003. Available at http://www.reliefweb.int/w/rwb.nsf/0/43d32d922cd863bec1256cb500347a15?OpenDocument. Accessed March 2003.

18 World Food Program. AIDS complicating battle against hunger, says WFP Executive Director. News release [online], 11 May 2004. Available at http://www.wfp.org/newsroom/subsections/ preview.asp?content_item_id=1597\&item_id=936\&section=13. Accessed June 2004.

19 United Nations Administrative Committee on Coordination, Sub-committee on Nutrition (ACC/SCN). Fifth Report on the World Nutrition Situation. Geneva: ACC/SCN, 2004.

20 Mason JB, Bailes AB, Kendle A, Rivers J, Hudspeth C. Drought, HIV/AIDS, and Child Nutrition in Southern Africa. Part II. Nairobi: United Nations Children's Fund, Eastern and Southern Africa Regional Office, July 2004.

21 Mason JB, Bailes AB, Mason KE. Drought, AIDS, and Child Malnutrition in Southern Africa: Preliminary Analysis of Nutritional Data on the Humanitarian Crisis. Report prepared for United Nations Children's Fund, Eastern and Southern Africa Regional Office, Nairobi, Kenya, May 2003.

22 United Nations Children's Fund (UNICEF). Nutrition: southern Africa humanitarian crisis. Presentation at an inter-agency meeting convened by UNICEF and World Food Program, Johannesburg, South Africa, April 2003 [online]. Available at http://www.sahims.net/doclibrary/ reg/reg_nipsa_presentation_april_2003_r12a_notes.pdf. Accessed June 2004.

23 United Nations Children's Fund (UNICEF), Eastern and Southern Africa Regional Office (ESARO). Drought, AIDS, and Child Malnutrition in Southern Africa: Analysis of Nutritional Data on the Humanitarian Crisis. Nairobi: UNICEF/ESARO, May 2004.

24 ORC Macro. Demographic and Health Surveys [online]. Available at http://www.measuredhs.com. Accessed March 2003.

25 United Nations Children's Fund. Multiple Indicator Cluster Surveys [online]. Available at http://www.childinfo.org/ MICS2/Gj99306k.htm. Accessed March 2003.

26 United Nations Children's Fund, Division of Evaluation, Policy and Planning/Programme Division. Monitoring Progress Toward the Goals of the World Summit for Children End-Decade Multiple Indicator Survey Manual [online], 2000. Available at http://www.cpc.unc.edu/measure/guide/ tools/mics/manual.pdf. Accessed March 2003.

27 The National AIDS Control Programme, The POLICY Project. Estimating National HIV Prevalence in Malawi from Sentinel Surveillance Data [online], 2001. Available at http://www.
policyproject.com/pubs/countryreports/Malss.pdf. Accessed March 2003.

28 Central Statistical Office (Zambia). Central Board of Health (Zambia) and ORC Macro. Zambia Demographic and Health Survey 2001-2002. Zambia and Calverton, MD: Central Statistical Office, Central Board of Health and ORC Macro, 2003

29 Southern African Development Community (SADC)/Food, Agricultural and Natural Resources (FANR) Vulnerability Assessment Committee. Zimbabwe Emergency Food Security Assessment Report. Harare: SADC/FANR, January 2003.

30 World Health Organization (WHO) and Joint United Nations Programme on HIV/AIDS. Reconciling Antenatal Clinicbased Surveillance and Population-based Survey Estimates of HIV Prevalence in Sub-Saharan Africa. Geneva: WHO, August 2003. Also available at http://www.who.int/hiv/ strategic/en/lusaka_report.doc

31 United Nations Administrative Committee on Coordination, Sub-committee on Nutrition (ACC/SCN). Fourth Report on the World Nutrition Situation. Geneva: ACC/SCN, 2000; 11.

32 United Nations Administrative Committee on Coordination, Sub-committee on Nutrition (ACC/SCN). Update on the World Nutrition Situation: Recent Trends in Nutrition in 33 Countries. Geneva: ACC/SCN, 1989; 21.

33 Gaspar M, Cossa H, Santos CR, Manjate RM, Schoemaker J. Inquérito Demográfico e de Saúde 1997 [Mozambique Demographic and Health Survey 1997]. Calverton, MD: Instituto Nacional de Estatistica and Macro International Inc., 1998.

\section{Appendix - Data sources}

This appendix list additional data sources by country.

\section{Lesotho}

1. Government of Lesotho, Food and Nutrition Coordinating Office, Irish Aid and United Nations Children's Fund (UNICEF). National Nutrition and EPI Cluster Survey (NNEPI). Maputo: Government of Lesotho, Irish Aid and UNICEF, October 2002.

2. Southern African Development Community (SADC)/ Food, Agricultural and Natural Resources (FANR) Vulnerability Assessment Committee. Lesotho Emergency Food Security Assessment Report. Harare: SADC/FANR, January 2003.

3. Southern African Development Community (SADC)/ Food, Agricultural and Natural Resources (FANR) Vulnerability Assessment Committee. Lesotho Emergency Food Security Assessment Report. Harare: SADC/FANR, September 2002.

4. Joint United Nations Programme on HIV/AIDS/World Health Organization. Epidemiological Fact Sheets on HIV/AIDS and Sexually Transmitted Infections Lesotho 2002 Update [online], 2002. Available at http://www.who.int/GlobalAtlas/PDFFactory/HIV/ index.asp. Accessed March 2003.

5. Government of Lesotho, Bureau of Statistics and United Nations Children's Fund. Kingdom of Lesotho 2000 End of Decade Multiple Indicator Cluster Survey (EMICS). Draft Preliminary Report, May 2002. 


\section{Malawi}

1. NGO District Surveys. Unpublished results, available from United Nations Children's Fund, Malawi.

2. Southern African Development Community (SADC)/ Food, Agricultural and Natural Resources (FANR) Vulnerability Assessment Committee. Malawi Emergency Food Security Assessment Report. Harare: SADC/FANR, January 2003.

3. Famine Early Warning Systems Network (FEWS NET). Malawi Monthly Food Security Report, Mid-January 2003 to Mid-February 2003 [online], February 2003. Available at http://www.fews.net/centers/files/ Malawi_200301en.pdf. Accessed March 2003.

4. Famine Early Warning Systems Network (FEWS NET). Malawi Monthly Food Security Report, Mid May-Mid June 2002 [online], June 2002. Available at http://www. fews.net/centers/files/Malawi_200205en.pdf. Accessed March 2003.

5. Famine Early Warning Systems Network (FEWS NET). Malawi Monthly Food Security Report, Mid-November to Mid-December, 2002 [online], December 2002. Available at http://www.fews.net/centers/files/ Malawi_200212en.pdf. Accessed March 2003.

6. Joint United Nations Programme on HIV/AIDS/World Health Organization. Epidemiological Fact Sheets on HIV/AIDS and Sexually Transmitted Infections Malawi 2002 Update [online], 2002. Available at http://www.who.int/GlobalAtlas/PDFFactory/HIV/ index.asp. Accessed March 2003.

7. National Statistical Office (Malawi) and ORC Macro. Malawi Demographic and Health Survey 2000. Zomba, Malawi and Calverton, MD: National Statistical Office and ORC Macro, 2001.

8. Ministry of Economic Planning and Development, National Statistical Office and the Centre for Social Research. Malawi Social Indicators Survey 1995. Zomba, Malawi: Ministry of Economic Planning and Development, National Statistical Office and the Centre for Social Research, September 1996.

\section{Mozambique}

1. Famine Early Warning Systems Network (FEWS NET) Mozambique Monthly Food Security Report Mid-January to Mid-February, 2003 [online], 2003. Available at http:// www.fews.net/centers/current/monthlies/report/?f= $\mathrm{mz} \& \mathrm{~m}=1000838 \& \mathrm{l}=\mathrm{en}$. Accessed March 2003.

2. Government of Mozambique and United Nations Children's Fund (UNICEF). Multi-sectoral Assessment 2002: Second Multi-sectoral Assessment on the Impact of the Humanitarian Crisis on the Lives of Children and Women in Mozambique. Harare: Government of Mozambique and UNICEF, November-December 2002.

3. Southern African Development Community (SADC)/ Food, Agricultural and Natural Resources (FANR) Vulnerability Assessment Committee. Mozambique
Emergency Food Security Assessment Report. Harare: SADC/FANR, September 2002.

4. Joint United Nations Programme on HIV/AIDS/World Health Organization. Epidemiological Fact Sheets on HIV/AIDS and Sexually Transmitted Infections Mozambique 2002 Update [online], 2002. Available at http://www.who.int/GlobalAtlas/PDFFactory/HIV/ index.asp. Accessed March 2003.

5. Gaspar M, Cossa H, Santos CR, Manjate RM, Schoemaker J. Inquérito Demográfico e de Saúde 1997 [Mozambique Demographic and Health Survey 1997]. Calverton, MD: Instituto Nacional de Estatistica and Macro International Inc., 1998.

\section{Swaziland}

1. United Nations Children's Fund (UNICEF). Lumbombo (Swaziland) Regional Survey 2002: The Nutrition and Health Status of Children 6-59 months in the Lubombo Region. Maseru: UNICEF, December 2002.

2. Southern African Development Community (SADC)/ Food, Agricultural and Natural Resources (FANR) Vulnerability Assessment Committee. Swaziland Emergency Food Security Assessment Report. Harare: SADC/FANR, December 2002.

3. Southern African Development Community (SADC)/ Food, Agricultural and Natural Resources (FANR) Vulnerability Assessment Committee. Swaziland Emergency Food Security Assessment Report. Harare: SADC/FANR, September 2002.

4. Joint United Nations Programme on HIV/AIDS/World Health Organization. Epidemiological Fact Sheets on HIV/AIDS and Sexually Transmitted Infections Swaziland 2002 Update [online], 2002. Available at http://www.who.int/GlobalAtlas/PDFFactory/HIV/ index.asp. Accessed March 2003.

5. Central Statistical Office, Government of Swaziland. Multiple Indicator Cluster Survey: Full Report. Maseru: Central Statistical Office, Government of Swaziland, 2000.

\section{Zambia}

1. Southern African Development Community (SADC)/ Food, Agricultural and Natural Resources (FANR) Vulnerability Assessment Committee. Zambia Emergency Food Security Assessment Report. Harare: SADC/FANR, January 2003.

2. Southern African Development Community (SADC)/ Food, Agricultural and Natural Resources (FANR) Vulnerability Assessment Committee. Zambia Emergency Food Security Assessment Report. Harare: SADC/FANR, September 2002.

3. Famine Early Warning Systems Network (FEWS NET). Zambia Monthly Food Security Report Mid-January to Mid-February, 2003 [online], March 2003. Available at 
http://www.fews.net/special/index.asp?f=alpage $=$ specialdoc\&g=1000256. Accessed March 2003.

4. Joint United Nations Programme on HIV/AIDS/World Health Organization. Epidemiological Fact Sheets on HIV/AIDS and Sexually Transmitted Infections Zambia 2002 Update [online], 2002. Available at http://www.who.int/GlobalAtlas/PDFFactory/HIV/ index.asp, Accessed March 2003.

5. Central Statistical Office (Zambia), Central Board of Health (Zambia) and ORC Macro. Zambia Demographic and Health Survey 2001-2002. Calverton, MD: Central Statistical Office, Central Board of Health and ORC Macro, 2003.

6. Government of Zambia and United Nations Children's Fund (UNICEF). Zambia 1999 Multiple Indicator Cluster Survey: Report on the Monitoring of the End of Decade Goals. Maryland: Government of Zambia and UNICEF, 1999.

7. Central Statistical Office (Zambia), Ministry of Health and Macro International Inc. Zambia Demographic and Health Survey, 1996. Calverton, MD: Central Statistical Office and Macro International Inc., 1997.

\section{Zimbabwe}

1. Government of Zimbabwe. National Nutrition Survey 2002: A National Assessment of the Nutritional Status Situation. Harare: Government of Zimbabwe, May 2002.

2. Southern African Development Community (SADC)/ Food, Agricultural and Natural Resources (FANR) Vulnerability Assessment Committee. Zimbabwe Emergency Food Security Assessment Report. Harare: SADC/FANR, January 2003.

3. Joint United Nations Programme on HIV/AIDS/World Health Organization. Epidemiological Fact Sheets on HIV/AIDS and Sexually Transmitted Infections -
Zimbabwe 2002 Update [online], 2002. Available at http://www.who.int/GlobalAtlas/PDFFactory/HIV/ index.asp. Accessed March 2003.

4. Central Statistical Office (Zimbabwe) and Macro International Inc. Zimbabwe Demographic and Health Survey 1999. Calverton, MD: Central Statistical Office and Macro International Inc., December 2000.

5. Central Statistical Office (Zimbabwe) and Macro International Inc. Zimbabwe Demographic and Health Survey 1994. Calverton, MD: Central Statistical Office and Macro International Inc., September 1995.

\section{General}

1. Southern African Development Community/Food, Agricultural and Natural Resources Vulnerability Assessment Committee. The impact of HIV/AIDS on food security in southern Africa. Draft for stakeholder presentation at an inter-agency meeting convened by United Nations Children's Fund and World Food Program in Johannesburg, South Africa in April 2003, March 2003.

2. Southern African Development Community (SADC)/ Food, Agricultural and Natural Resources (FANR) Vulnerability Assessment Committee. Regional Emergency Food Security Assessment Report. Harare: SADC/FANR, September 2002.

3. Southern African Development Community (SADC)/ Food, Agricultural and Natural Resources (FANR) Vulnerability Assessment Committee. Regional Emergency Food Security Assessment Report. Harare: SADC/FANR, January 2003.

4. United Nations Administrative Committee on Coordination, Sub-committee on Nutrition (ACC/SCN) in collaboration with International Food Policy Research Institute. Fourth Report on the World Nutrition Situation. Geneva: ACC/SCN, 2000. 